\author{
Zbigniew Pater*, Jan Kazanecki**
}

\title{
THERMO-MECHANICAL ANALYSIS OF PIERCING PLUG LOADS IN THE SKEW ROLLING PROCESS OF THICK-WALLED TUBE SHELL
}

\section{INTRODUCTION}

The skew rolling process is a widely applied method of manufacturing of thick-walled tube shells. In this process the following tools were used: two or sometimes three rolls (put askew to the rolled tube shell axis), piercing plug sizing the tube internal diameter and (in the case of two rolls method) guiding devices keeping the workpiece in the area between rolls. The piercing plug has the worst working conditions in the skew rolling process because this tool is heated to high temperatures during forming. This situation, together with high pressure at the metal-plug surface of contact, requires frequent changes of the piercing plug for a new one [1].

Predicting the plug temperature is very important in increasing this tools durability. Because the measuring of temperature in the plug during rolling is quite complicated, it is advisable to find an alternative method of predicting of this tool effort. It seems that the ideal solution of this problem is numerical modelling of the skew rolling process in such way that it will be possible to determine the distributions of stress and temperatures in the piercing plug. In recent years, few models of the piercing process in skew rolling mill have been worked out [2-5]. However, these models had a lot of simplifications connected e.g. with omitting of thermal phenomena, in calculations. Moreover, in all solutions it was assumed that tools were rigid bodies which made impossible to analyse their load in details.

Aiming at precise representation of real conditions, the authors worked out a new model of piercing process in skew rolling mill, in which thermal phenomena present during forming were considered. In this model, it was assumed that the piercing plug could be deformed in elastic range which allowed for determining the thermo-mechanical loads of this tool during the piercing process in skew rolling mill.

* D.Sc., Ph.D.: Mechanical Department, Lublin University of Technology, Lublin, Poland; z.pater@pollub.pl

** Prof., D.Sc., Ph.D.: Faculty of Metals Engineering and Industrial Computer Science, AGH University of Science and Technology, Cracow, Poland; kazaneck@metal.agh.edu.pl 


\section{DESCRIPTION \\ OF THE APPLIED FEM MODEL}

For the analysis of the piercing process in the skew rolling mill the commercial software MSC.SuperForm 2005, which uses displacement FEM representation, was applied. This software was earlier successfully used by one of the authors for numerical simulation of cross wedge rolling processes [6-8]. Due to the complexity, the piercing process in the skew rolling mill should be simulated only in the 3D state of strain conditions.

During the analysis, the piercing process of the tube shell in the two rolls rolling mill with the guiding devices of Diescher type was considered. The schema of this process is presented in Figure 1, in which the basic geometrical parameters were also marked. It was assumed that: cylindrical billet from steel of $100 \mathrm{Cr} 6$ type (with dimensions $\emptyset 60 \times 120 \mathrm{~mm}$ ) was used as charge, the rolls rotated in the same direction with the same rotary speed $n$ $=60 \mathrm{rpm}$, the disc guiding devices rotated (in the opposite direction) with the speed $6.8 \mathrm{rpm}$, the reduction ratio in the area between rolls was $16 \%$, the coefficient of ovalization was 1.05 .

In Figure 2 the worked out FEM model of the piercing process according to the schema from Figure 1 is presented. This model consists of two barrel rolls and two disc guiding devices (modelled as rigid bodies), piercing plug and billet. Additionally, a pusher was used in order to place the billet in the area between rolls (this pusher cannot be noticed in Fig. 2). For billet modelling hexahedral elements were applied.

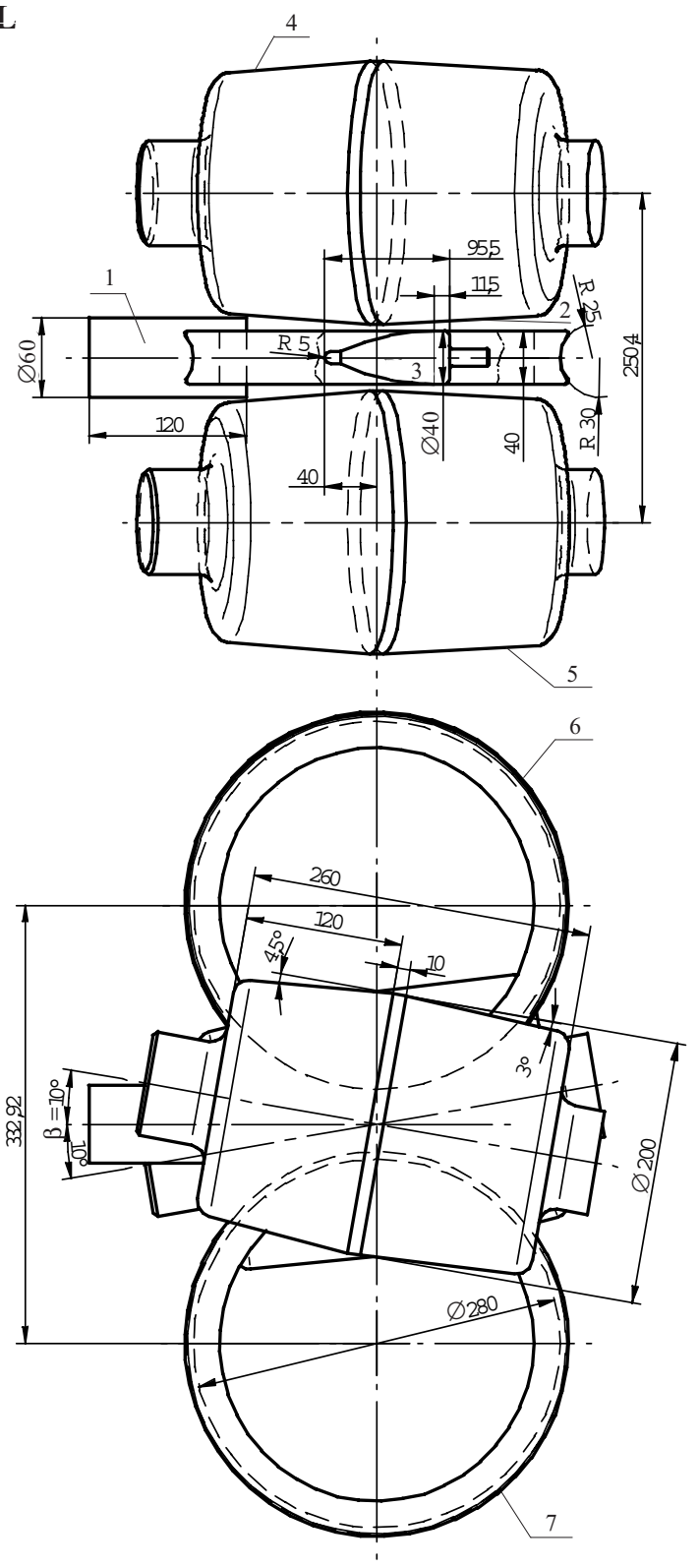

Fig. 1. Schema of the piercing process in the skew rolling mill equipped with guiding devices of Diescher type: 1 - billet, 2 - tube hollow, 3 -plug, 4 -roll No. 1 , 5 -roll No. 2, 6-Discher disk No. 1, 7 -Discher disk No. 2 (feed angle $\beta=10^{\circ}$, cross angle $\gamma=0^{\circ}$ ) 
The choice of elements resulted from the necessity of repeated application du-ring calculations of remeshing of elements modelling the workpiece. The moment in which the remeshing is done depended on the increase of strain value. The piercing plug was modelled by means of 4200 elements, which could be deformed only in the elastic range. However, the nodes of plug in the rotation axis were fixed.

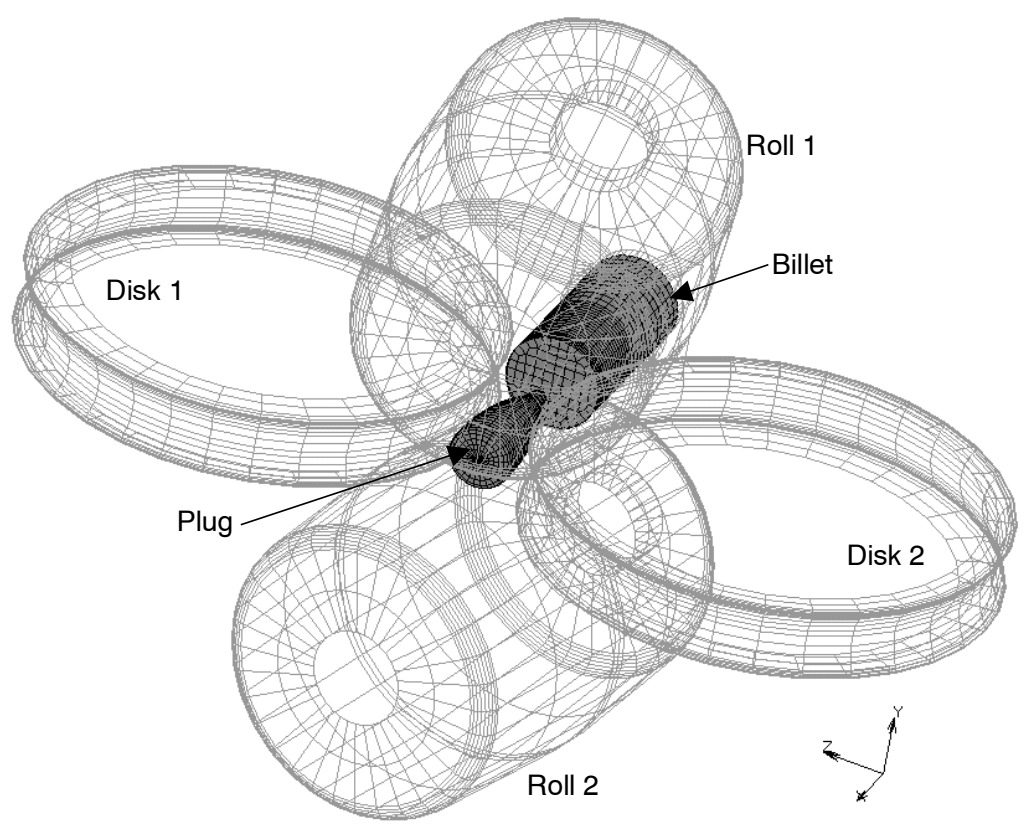

Fig. 2. FEM model of the piercing process in the skew rolling mill

The thermo-mechanical schema of calculations was considered. It was assumed that the billet was heated to the temperature $1180^{\circ} \mathrm{C}$ and the temperature of rigid tools (rolls and guiding devices) was constant during the whole forming process and it was $50^{\circ} \mathrm{C}$. In the case of plug, it was assumed that the temperature of this tool was the same as the environment temperature and it was $30^{\circ} \mathrm{C}$. On the basis of the work [9], it was stated that the coefficient of heat exchange between the tools and formed material was $4000 \mathrm{~W} /\left(\mathrm{m}^{2} \cdot \mathrm{K}\right)$. However, the value of this coefficient determining the heat exchange between the metal and environment was $200 \mathrm{~W} /\left(\mathrm{m}^{2} \cdot \mathrm{K}\right)$.

The model of the formed material - steel of 100Cr6 type - was taken from the library of the software MSC.SuperForm 2005. However, the model of the material form which the piercing plug was made was described in a unique way by:

- Young module - $324000 \mathrm{~N} / \mathrm{mm}^{2}$,

- Poisson coefficient -0.3 ,

- density $-8120 \mathrm{~kg} / \mathrm{m}^{3}$,

- coefficient of heat conduction $27.6 \mathrm{~W} /(\mathrm{m} \cdot \mathrm{K})$,

- specific heat $-456 \mathrm{~J} /(\mathrm{kg} \cdot \mathrm{K})$. 
In the analysis constant friction model was assumed, which depended on the slip velocity between metal and tools. Due to the lack of lubrication and the purposeful roughness of rolls (for the easier placing of billet in the area between rolls), it was assumed that the friction factor for rolls had the limiting value $m=1.0$. However, because of the fact that during piercing the rotating workpiece put the plug into the rotary movement, the friction of the surface of contact between the plug and material was omitted in the calculations. In the result of such a solution the friction factor between the guiding device and formed metal decreased to the value of 0.3 (in order to balance the friction forces present on the disc guiding device and piercing plug).

\section{RESULTS OF CALCULATIONS}

Due to the application of FEM it was possible to analyse precisely the changes of shape of workpiece during the piercing process. These changes are presented in Figure 3 in which, in order to improve the readability, one of the guiding devices was omitted. At the beginning of the process, the billet is clamped by rolls which put it into rotary motion and later transmit it in the axial direction. The process of rotational compression by two tools is then realized and it lasts till the head surface of workpiece has contact with the plug. Next, the process of forming of the tube shell internal hole begins; its size is determined by the dimension of the applied piercing plug. After the time $t=3 \mathrm{~s}$, the guiding devices contact with the billet. Their movement leads to the increase of axial forces which favour putting the billet on the piercing plug. The piercing process reaches the stable phase which is characterized by relative stability of forming forces, after the time $t \approx 5 \mathrm{~s}$.

Using the FEM method, the changes of state of strain during rolling in the skew rolling mill can be analysed in details. In Figure 4 the distributions of strains determined for the stable piercing stage $(t=5.5 \mathrm{~s})$ in the longitudinal and transverse planes are shown. From the data presented in this Figure it can be noticed that strains are put in a laminar way. However, the biggest strains are present in the external layers of the formed tube shell. On the basis of Figure 4, the changes of the workpiece cross section along the whole length of the forming area can be analysed. Due to the rolls influence ovalization of the cross section appears, which has the largest values in the cylindrical area of the piercing plug. This ovalization is finally removed after the movement of metal through the plug, where the tube shell gains the required circular shape.

In Figure 5 distributions of mean stress $\sigma_{m}$ in the longitudinal sections of the billet and piercing plug are presented. From these distributions result that the lowest stresses are in the area where the plug nose influences the formed metal. It should be noticed that in the analysed case the piercing of tube shell hole takes place only as the effect of mesh deformation. This process can lead to the overestimating of values of the calculated contact pressures and stresses of the plug nose in comparison with the real values. This happens because, in practice, due to the influence of large tensile stresses (well visible in Fig. 5) on the workpiece axial area, the material structure undergoes decohesion which makes forming of a hole possible. 

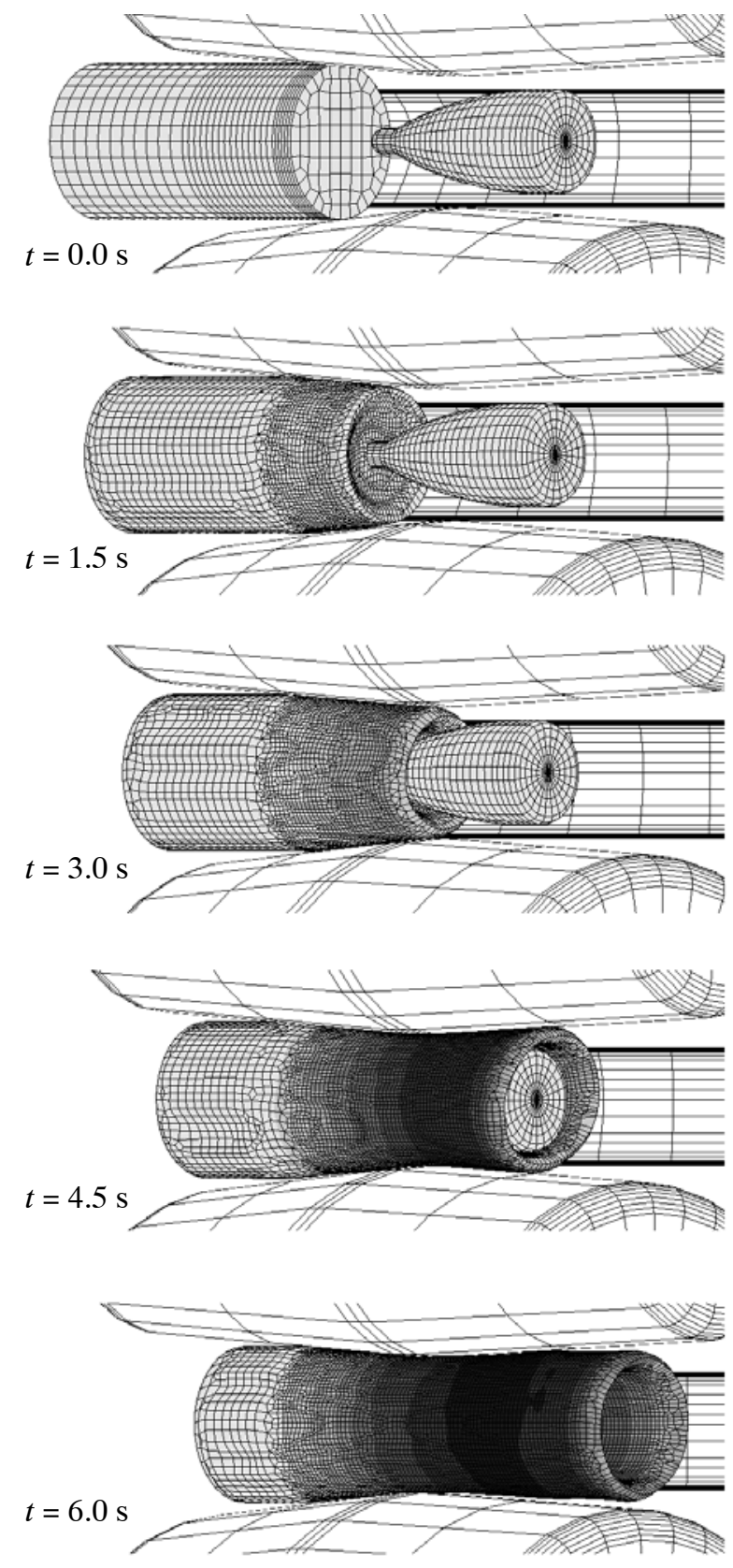

$\begin{array}{llllllllll}0.0 & 1.5 & 3.0 & 4.5 & 6.0 & 7.5 & 9.0 & 10.5 & 12.0 & \varepsilon_{i},-\end{array}$

Fig. 3. Changes of the workpiece shape during the piercing process in the skew rolling mill, together with the strain distribution 


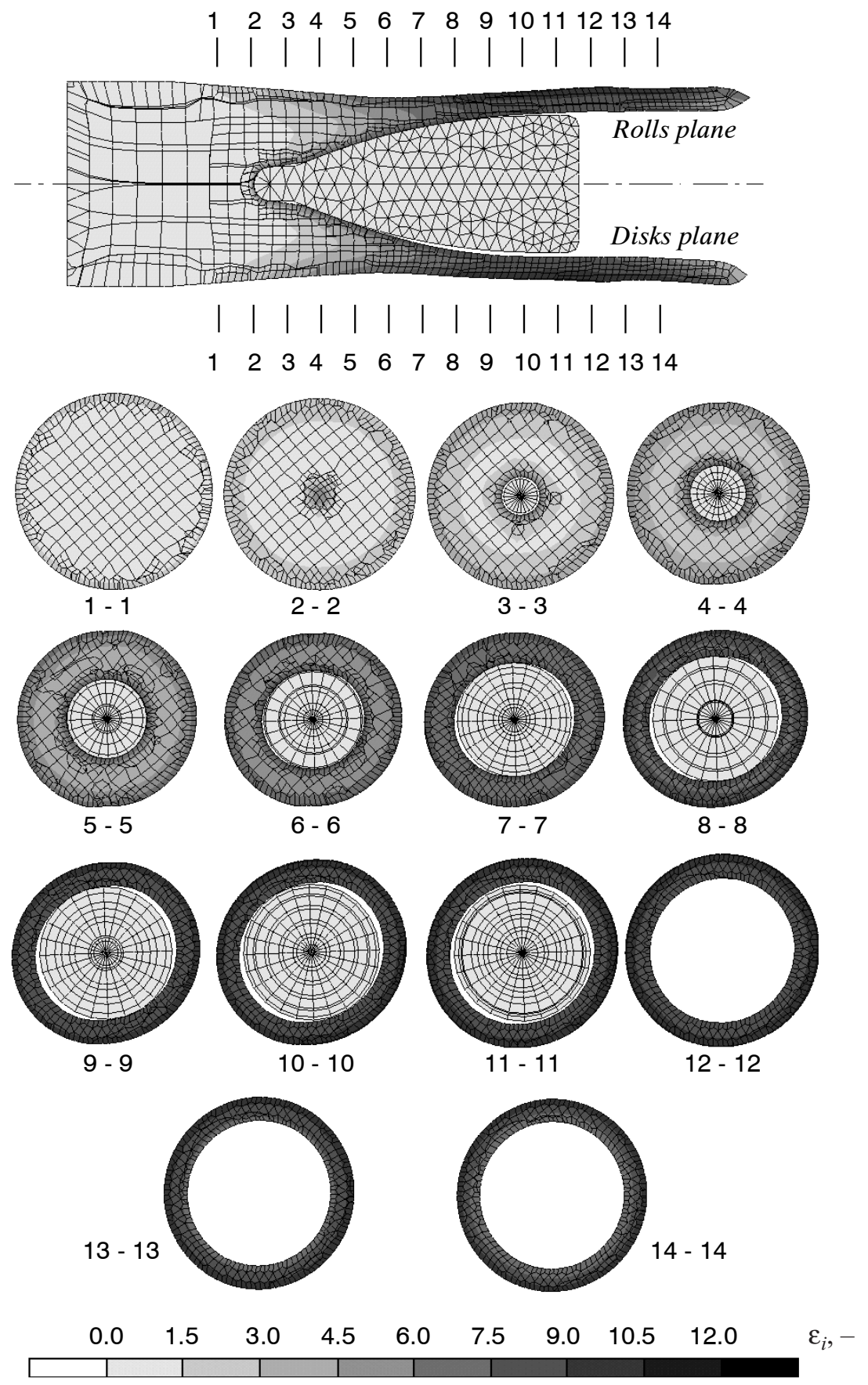

Fig. 4. Forming zone in the stable phase $(\mathrm{t}=5.5 \mathrm{~s})$ of the piercing process in the skew rolling mill, together with the strain distribution 
a)

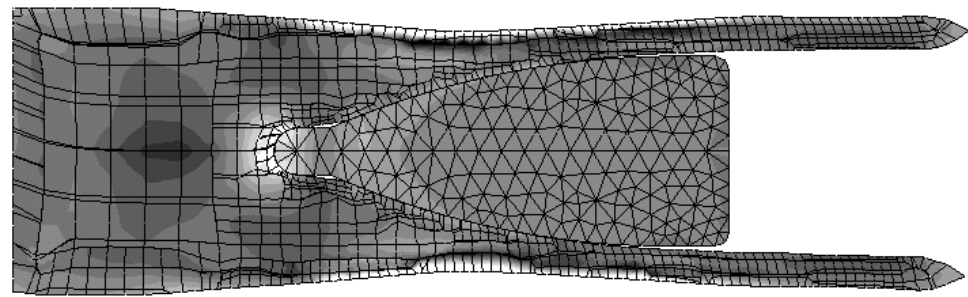

b)

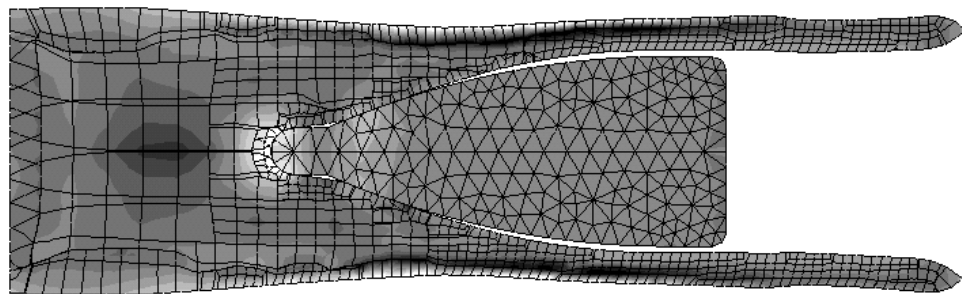

$\begin{array}{llllllllllll}-100 & -80 & -60 & -40 & -20 & 0 & 20 & 40 & 60 & 80 & 100 & \sigma_{m}, \mathrm{MPa}\end{array}$

Fig. 5. Distributions of mean stress in the billet and plug determined for the stable phase of the piercing process $(\mathrm{t}=5.5 \mathrm{~s})$ : a) rolls plane; b) disks plane

A more precise evaluation of the plug effort during forming can be obtained from the analysis of principal stresses distributions, determined for this tool and showed in Figure 6 .

In Figure 7 the changes of the plug temperature during piercing is presented. From the analysis of data in Figures 6 and 7 result, that in the most hard working part of the plug-nose three-axial compressive stresses appear. This is a favorable phenomenon as it does not cause cracks and shape deformation, even though the tool temperatures in this area are high (above $1100^{\circ} \mathrm{C}$ ). In the least loaded cylindrical part of the plug, the stresses characteristic for elongation processes appear (two-axial squeezing with axial stretching). However, in this part the plug has a lower temperature and, because of that, it is resistant to deformation.

In Figure 8 the changes of temperature on the plug surface in the chosen seven nodes are shown. The fact that the plug nose is heated to the temperature about $1150^{\circ} \mathrm{C}$ at the time $t \approx 1.5 \mathrm{~s}$ is of great importance. Hence, in numerical calculations of the piercing process, in which the plug is considered as the rigid body, the temperature of this tool should be assumed as slightly lower than the temperature of the formed material.

According to Figure 9, it is stated that the biggest contact pressures are at the piercing plug nose, where they reach values within the range of $100 \div 180 \mathrm{MPa}$. Considerably lower pressures (lower than $50 \mathrm{MPa}$ ) are noticed in the plug conical area, yet, these pressures are localized in the rolls plane. The determined values of contact pressures are the same as the values provided in the reference [1] and dealing with forming of alloyed steel. This confirms the proper modelling of the piercing process in the skew rolling mill equipped with discs guiding devices. 


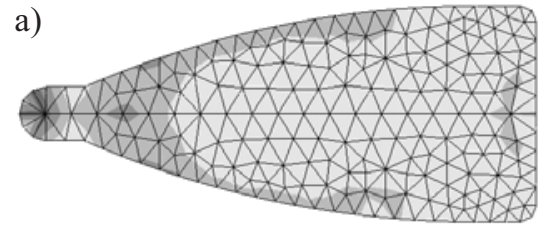

b)

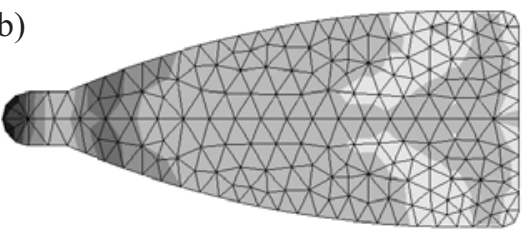

c)

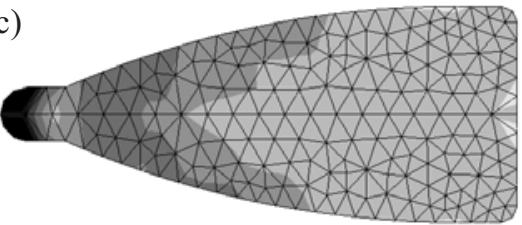

$p_{n}, \mathrm{MPa}$

$\begin{array}{lllllll}-100 & -80 & -60 & -40 & -20 & 0 & 20\end{array}$

Fig. 6. Distributions of principal stresses in the piercing plug at the stable phase of the piercing process in the skew rolling mill $(t=5.5 \mathrm{~s})$ for principal streses: a) first; b) second; c) third

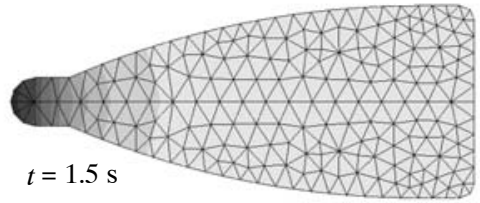

$\mathrm{t},{ }^{\circ} \mathrm{C}$

1150

1050

950

850

750

650

550

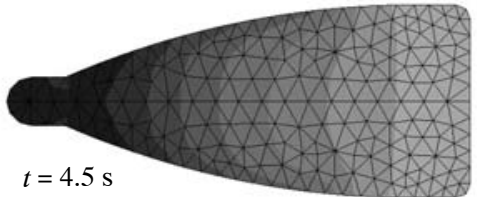

450

350

250

150

50

Fig. 7. Distributions of temperatures in the piercing plug in the forming process in the skew rolling mill

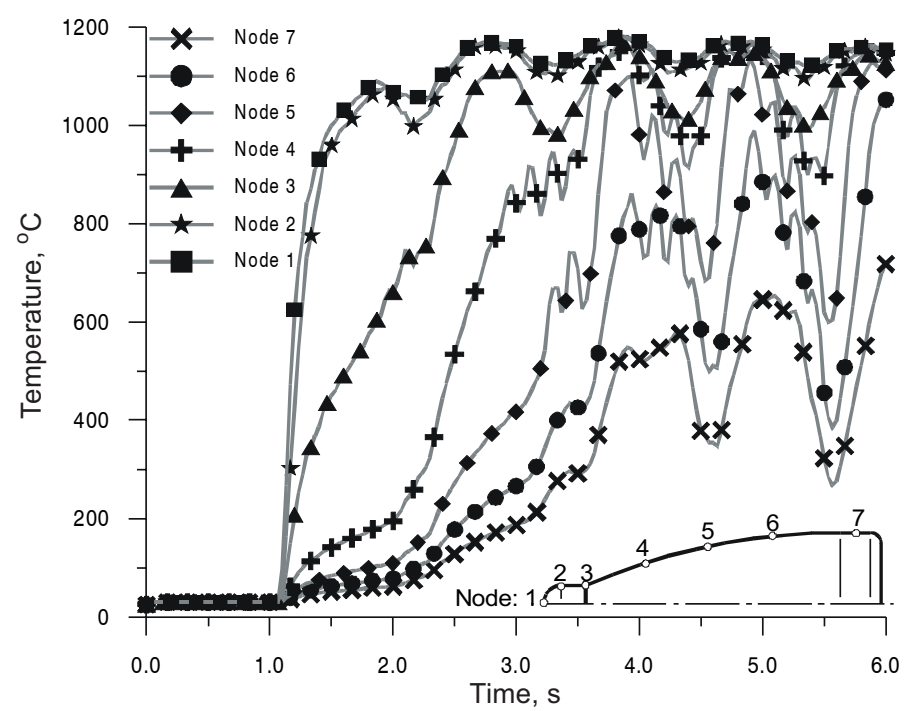

Fig. 8. Changes of temperatures on the plug surface during the piercing process in the skew rolling mill 

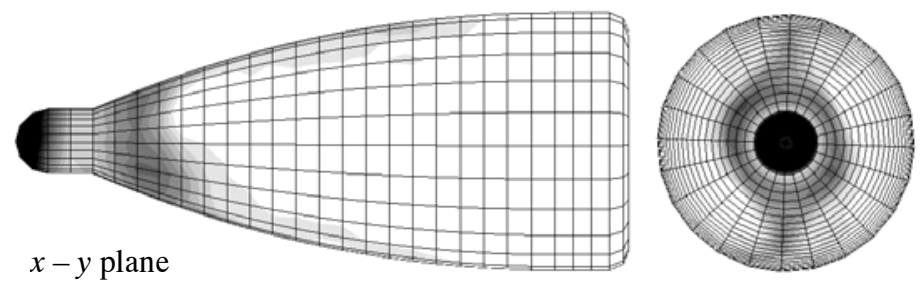

$$
y-z \text { plane }
$$

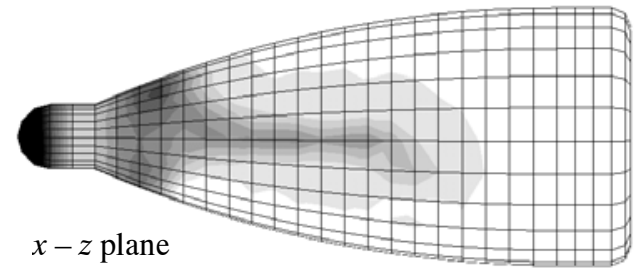

$x-z$ plane

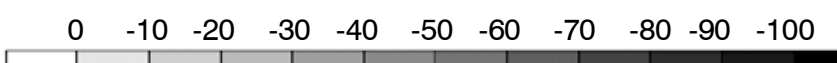

$p_{n}, \mathrm{MPa}$

Fig. 9. Contact pressures on the piercing plug surface at the stationary phase of the piercing process in the skew rolling mill

\section{SUMMARY}

In this paper, the model of thermo-mechanical piercing process in the skew rolling mill aiming at the analysis of the piercing plug effort is described. Applying this model and the commercial software MSC. SuperForm 2005, numerical simulation of the whole piercing process was made. In the results of calculations, distributions of strains and stresses in the workpiece and piercing plug were determined. It was stated that the most hard working part of the plug was its nose, where the unit pressures had the values exceeding $100 \mathrm{MPa}$. At the same time, the temperature in this tool area quickly approached the temperature of the formed metal. It should be also noted that the piercing model can be developed in such away that it will be possible to assume different material parameters for the plug nose. In the nearest future, the authors plan to make experimental research. Their results will be used for verification of the worked out model.

Research work paid by The State Committee for Scientific Research in the year 20052008 as project No. 3 T08B03929.

\section{REFERENCES}

[1] Kazanecki J.: Wytwarzanie rur bez szwu. UWND AGH, Kraków, 2003

[2] Urbański S., Kazanecki J.: Assessment of the strain distribution in the rotary piercing process by the finite element method. Journal Materials Processing Technology, 45 (1994), 335-340

[3] Pietsh J.: Thievien. FEM simulation of the rotary tube piercing process. MPT International, 2 (2003), 52-60 
[4] Ceretti E. et al.: Rotary tube piercing study by FEM Analysis: 3D simulations and Experimental Results. Tube \& Pipe Technology March/April 2004, 155-159

[5] Komori K.: Simulation of Mannesmann piercing process by the three-dimensional rigid-plastic finite-element method. International Journal of Mechanical Sciences, 47 (2005), 1838-1853

[6] Pater Z.: Stress state in cross wedge rolling process. Archives of Metallurgy, 48 (2003), 21-35

[7] Pater Z.: Finite element analysis of cross wedge rolling. The Arabian Journal for Science and Engineering, 30 (2005) 1C, 27-37

[8] Pater Z., Bartnicki J., Samolyk G.: Numerical modelling of cross-wedge rolling process of ball pin. Journal of Materials Processing Technology, 164-165 (2005), 1235-1240

[9] Prince J.C., Marono R., Leon F.: Thermomechanical analysis of a piercing mandrel for the production of seamless steel tubes. Proc. Instn Mech. Engrs, vol. 217, Part E: J. Process Mechanical Engineering, 337344

Received

April 2006 